\title{
Do Evaluative Pressures and Group Identification Cultivate Competitive Orientations and Cynical Attitudes Among Academics?
}

\author{
Tobias Johansson ${ }^{1,2}$ (D)
}

Received: 1 April 2020 / Accepted: 31 October 2020 / Published online: 13 November 2020

(c) The Author(s) 2020

\begin{abstract}
This article theorizes and analyzes how two aspects of the increasing accountingization of academia in the form of evaluative pressures and group identification, independently and interactively, work to cultivate academics' self-interest for their social interactions with the scientific community, forming them to adopt more competitive orientations and cynical attitudes. Using data of a large number of faculty members from the 17 universities in Sweden, it is shown that evaluative pressures and group identification perceived by academics jointly reinforce each other (interact) in affecting their competitive orientation, and that group identification strengthens (moderates) the positive relation between evaluative pressures and academics' rivalry notions and cynical attitudes. It is shown, contributing further to research on performance evaluation and the cultivation of self-interest and an egoistic ethical climate in academia, that it is evaluative pressures from peers rather than from performance measurements that are the major driver of an individual's competitive (less cooperative) orientation and cynical attitudes. It is also concluded that while evaluative pressures are related to an increase in academics' competitive orientations, which may be viewed as an intended effect from control designers in universities, such an orientation is inversely related to cooperativeness and openness toward others and goes hand in hand with an increase in having cynical attitudes about peers and the work environment. Control designers in universities may thus not be able to have the one without the other, something that raises ethical concerns for academic leaders to reflect upon when aiming at cultivating self-interest orientations of academics.
\end{abstract}

Keywords Performance evaluation · Peer pressure · Competition · Cynicism · Group identification · University · Survey

\section{Introduction}

Universities have become strongly influenced by managerialism, and academics are increasingly performance-evaluated and pressured to publish, perform more broadly, and compete (e.g., Parker 2011, 2013; Ter Bogt and Scapens 2012; Gendron 2015; Su and Baird 2017). Extensive case evidence exists of academics' altered orientations in the form of becoming more competitive and performance-oriented (e.g., Gendron 2008; Ter Bogt and Scapens 2012; Malsch and Tessier 2015; see also Kallio et al. 2016 for large N survey-based empirics on the broader topic), and of their adoption of a pay-off (self-interest) mentality (Gendron

\footnotetext{
Tobias Johansson

Tobias.johansson@oru.se

1 Örebro University, 70281 Örebro, Sweden

2 Mälardalen University, 72123 Västerås, Sweden
}

2008, 2015) as a consequence of evaluative practices and pressures in universities. Despite these research efforts and results, deepening our knowledge and empirical awareness of how evaluative pressures and the increasing accountingization of academia cultivate self-interest motivations of academics further is important because it raises the ethical and normative question of what should be the motivation and ethical climate (Victor and Cullen 1988) of researchers at universities and what it means for their social relations with the scientific community, relations that form scientific practices.

Thus, we need to better understand how performance evaluation pressures relate to increased self-interest orientations of academics and what it implies for the university institution. Self-interest motivation need not be unethical or immoral per se; it is what consequences and attitudes it potentially gives rise to (Kish-Gephart et al. 2014) and when self-interest implies, for example, selfishness (Maitland 2002) and greed (Shleifer 2004) that becomes the behavioral 
ethics issue in organizations (Treviño et al. 2014). If the fact that academics becoming more self-interest-oriented and competitive from being performance-evaluated means that their efforts to publish and apply for research grants are increased and that they perhaps become more occupied with prestige and rankings, these developments may not have a fundamental impact on the very nature of academic practices in universities (cf. Knights and Clark 2014). Some would argue that it is beneficial for productivity and research output. With a competitive orientation of individuals and research groups, however, comes a potential dilemma (Shleifer 2004) since a competitive interactive strategy likely means less of an orientation toward cooperation with and openness toward others (Deutsch 1949; Simmons et al. 1988; Tenbrunsel and Messick 1999). Cultivating academics' competitive orientation, thus, risks creating an uncooperative and individual-level egoistic ethical climate (Victor and Cullen 1988; Kish-Gephart et al. 2010) for academics' social interactions. This is a development and matter that, in the long-run, risks colliding with the overall ambition of the university institution: to contribute to the deepening of human knowledge for the good of all humans (e.g., Boulton and Lucas 2011).

A highly related issue that also calls for further research on the ethical aspects of the effects of evaluative pressures for academics' self-interest orientations and egoistic ethical climate is that an altered personal orientation of becoming more competitive and self-interest-oriented likely leads to a changed perspective on how to view upon "others" as also driven by their self-interest. Having the view that "others" (e.g., peers and employers) are driven primarily by their selfinterest is what cynicism (being cynical) is about (Andersson 1996; Turner and Valentine 2001; Vice 2011). A view that others have no virtues but are driven by their ego and selfbenefit motivations. Developing cynical attitudes about the research community (peers) and its practices are likely not a viable seedbed for academics and scientific practices since it has been associated with unethical and distrustful behaviors in organizations (Andersson 1996). Philosophical work on the nature of cynical attitudes concludes that "this attitude is hostile to the virtues of faith, hope and charity, upon which relationships and our sense of moral community depend" and that holding such attitudes are by themself immoral (Vice 2011, p. 169). Thus, while previous research on performance evaluation in academia has noted that evaluative pressures make academics more self-interest-oriented, if and to what extent this spills-over into cynical attitudes of others is pressing to uncover to create knowledge and empirical awareness of what evaluative pressures in organizations do to the ethical orientation of individuals (Treviño et al. 2014; Goebel and Weißenberger 2017).

Another evident effect of the managerial and accountingization development within the university sector is the increasing importance of the group as a unit of both competition and performance evaluation. "Accounting" not only adjudicates and subjectivizes academics in potentially becoming competitive and cynical; it also territorializes individuals into units of evaluation (e.g., labs, research groups, milieus, departments, etc.) (Miller and Power 2013). To contribute to knowledge about what this development implies for performance evaluation and self-interest orientation in academia I mobilize theory and research on the interindividual-intergroup discontinuity effect (Schopler and Insko 1992). From this theory follows the expectation that individual responses and the resulting attitude formations from evaluative pressures in organizations may differ by being more self-interest-oriented (in this study related to competitive orientation and cynical attitudes), depending on the extent to which individuals are embedded within and identify themselves with a group (or a similar type of collective). Individuals' group identification, potentially nourished by the accountingization within academia, may thus further cultivate competitive orientations and cynical attitudes among performance-evaluated academics for their social relations in the scientific community, both independently and in conjunction with evaluative pressures exerted at academics. This is something that makes the focus on academics' group identification (Ashforth and Mael 1989; Ellemers et al. 2002) highly relevant for research on (un) ethical attitudes and behaviors in organizations where a call for research involving groups and commitments to them (collective identification/identity) have been made (Treviño et al. 2014).

Aiming to address these concerns about the attitudinal effects connected to the cultivation of self-interest motivations by performance evaluation practices in universities, I develop hypotheses and a structural equation model linking evaluative pressures in the form of the perceived emphasis put on quantitative performance measures and peer pressure, and an individual's level of group identification to variables capturing an individual's competitive orientation and cynical attitudes about peers and the work environment. The model and hypotheses are tested with random sample survey data covering different science disciplines of a large number of faculty members $(N=711)$ from the 17 universities in Sweden.

The rest of the article is structured as follows: The next section further develops theoretical arguments and poses hypotheses to be tested. Then, the sample, survey, and instruments are described, followed by a statistical results presentation. The article ends with a discussion of its main findings and contributions. 
Fig. 1 Theoretical model

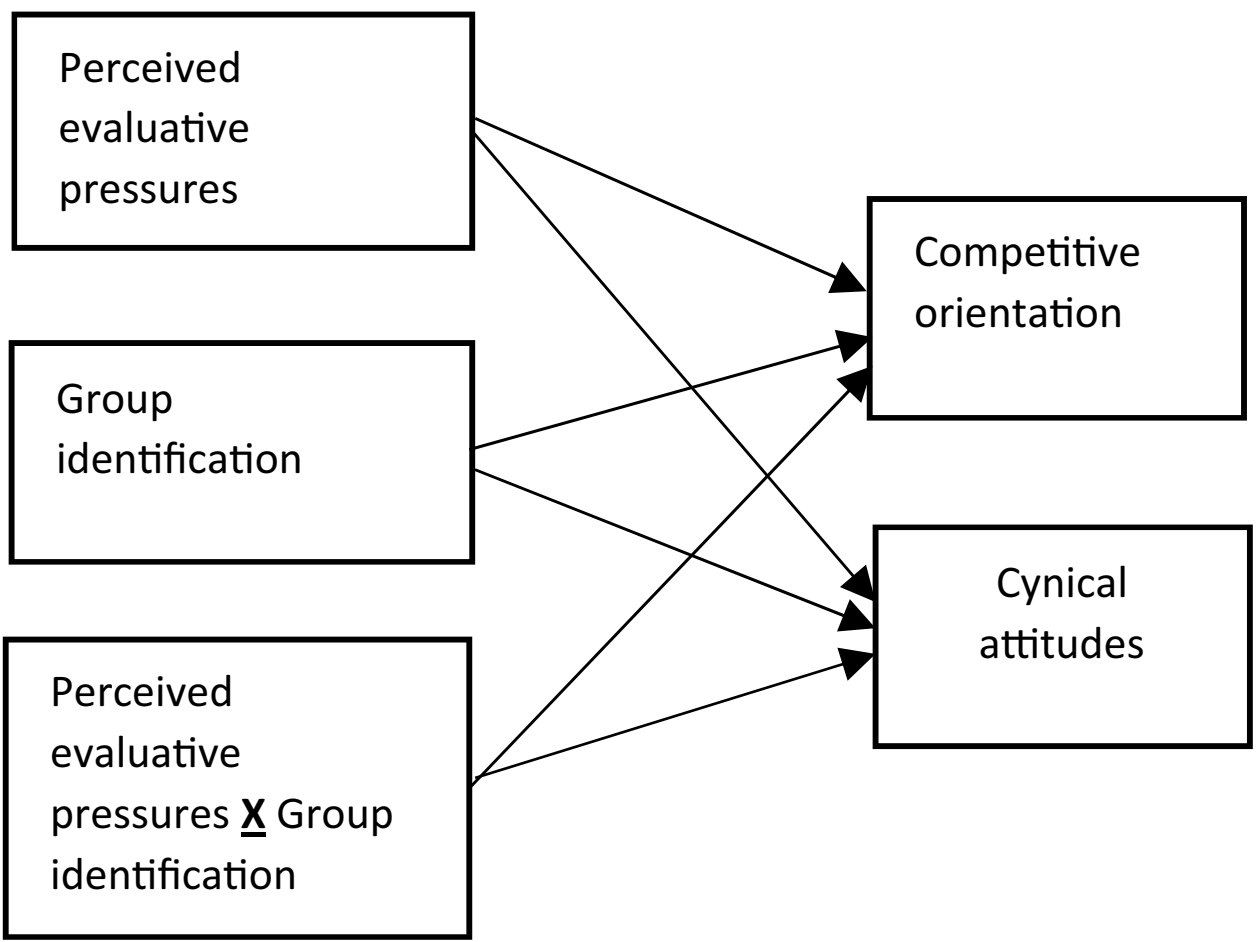

\section{Hypotheses Development}

This section develops a theoretical model proposing direct (main) effects as well as interactive effects from the perceived evaluative pressures of an individual and the level of group identification on an individual's competitive orientation and cynical attitudes. The theoretical model is shown in Fig. 1. The theorizing begins by developing the two hypotheses grounding the two direct effects and then theorizing (Hypothesis 3) how they interact. Because Hypothesis 3 (the last hypothesis) implies an exploration of whether evaluative pressures and group identification work as independent interactors or moderators (Luft and Shields 2003), the interaction in Fig. 1 is simply drawn as the product term between them.

\section{The Relationship Between Evaluative Pressures and Academics' Competitive Orientation and Cynical Attitudes}

Performance measures and evaluation practices in universities come in different forms. Previous accounting research has mainly focused on formal and "objective" systems such as journal rankings for promotion decisions (Malsch and Tessier 2015) and different performance measurement and evaluation systems used to evaluate and incentivize the performance of academics (e.g., Ter Bogt and Scapens 2012; $\mathrm{Su}$ and Baird 2017). This is natural, considering that the increasing use and sophistication of these formal systems are perhaps the most visible changes in how the profession of academics has become governed by university top management. As in most organizations, however, and with the history of academic work being a profession building on notions of collegiality specifically (Kallio et al. 2016), informal clan and peer types of controls (Ouchi 1980; Loughry 2010) are also important to consider to understand how pressures to perform are directed at academics and how academics are evaluated. This was very visible in the comparative case study by Ter Bogt and Scapens (2012), where actual performance measures played a secondary role compared to the evaluative pressure exerted by peers (a harsh publish-orperish culture) in the Manchester case (see also Barker 1993, on concertive control). This result aligns well with previous management control ethics research that has highlighted that it is informal, rather than formal, control that drives individuals' ethical dilemmas and climates (Falkenberg and Herremans 1995; Goebel and Weißenberger 2017). So, not only are academics increasingly measured and evaluated by formal performance measurement systems designed by university management, but they are also constantly assessed and evaluated by the often-strong norm structure from peers. And, since the changing landscape of academic work has also meant that the academic culture, and not only the administrative structures, have changed toward being performance and competition-focused (e.g., Kallio et al. 2016), both formal control in the form of performance measures and informal control in the form of peer pressure (Loughry 2010; De Jong et al. 2014) exert evaluative pressures on academics to perform (e.g., publish). Although departing from different perspectives and focusing on different aspects of 
evaluative pressures in universities, studies within the area have uniformly argued that academics have adopted more of a competitive orientation and a pay-off mentality as a consequence of these pressures (e.g., Gendron 2008; Knights and Clarke 2014; Kallio et al. 2016; Malsch and Tessier 2015). There is most likely more than one mechanism explaining this, and they stem from anything from classics agency theory notions that evaluative pressures direct attention to and incentivize such behaviors/orientations (Frey, Homberg, and Osterloh 2013; Jacobsen and Andersen 2014; Vogel and Hattke 2018), to notions of identity work by fragile academic selves that leads to compliance (Knights and Clarke 2014), and matters in between. When faced with an ethical dilemma (e.g., compete or cooperate?), moral reasoning will be guided by cues and stimuli from evaluative pressures in the organization (Victor and Cullen 1988). This theorizing aligns with the "bad barrels" argument of ethical behavior in organizations, that is, that the context and ethical culture surrounding individuals, such as those stemming from evaluative pressures (Treviño et al. 2014), strongly affect and direct humans in their ethical positions and behaviors.

Even if it can be debated if the pressure to be competitive and, for example, to aspire for publications in highly esteemed journals is mostly for good or bad (Knights and Clarke 2014), the performance-oriented evaluative pressure, due to its cultivation of self-interest, also has a potentially darker side to it by subjects adopting cynical attitudes (Andersson 1996; Vice 2011) of one's work context. A rather obvious, but in previous work on organizational cynicism, overlooked reason (Andersson 1996; Dean et al. 1998) for cynicism to emerge in organizations is that by changing the orientation of individuals in being more competitive and calculative, such self-interest motivations and a "pay-off mentality" (Gendron 2008, 2015) likely go hand in hand with a change in how one regards others as also being driven by their self-interest. According to the Merriam-Webster dictionary (1993, p. 323), a cynic is defined as "one who believes that human conduct is motivated wholly by self-interest", a definition that correlates closely with how Victor and Cullen (1988) developed their instrument to capture an individual-level egoistic ethical climate. Having cynical attitudes and outlooks about other individuals, one's employer, and "the system" might be detrimental and have been related to undesirable effects such as distrust, lack of organizational commitment, and unethical behaviors (e.g., Mirvis and Kanter 1989; Wanous et al. 2000). Philosophical work on the nature of cynical attitudes concludes that "this attitude is hostile to the virtues of faith, hope, and charity, upon which relationships and our sense of moral community depend", and that holding such attitudes are by themself immoral (Vice 2011, p. 169). Previous work on cynicism in organizations has convincingly argued for and shown that cynical attitudes are susceptible to change
(Mirvis and Kanter 1991; Anderson and Bateman 1997) and that they are a consequence of work-related pressures and the use of "management techniques" (Andersson 1996). Cynical attitudes are attitudes that, thus, have the potential to be affected by ethical cultures in organizations and are different from and unrelated to traits and dispositions such as negative affect, skepticism, and personality (Guastello et al. 1992; Wanous et al. 2000). So, in conclusion, not only is it likely that evaluative pressures stemming from performance measures and peer pressure, due to their cultivation of the self-interest, change the individual's orientation (how one views oneself) by personally becoming more competitively oriented; it also changes one's perspective of others (how one views others) as driven by their self-interest leading to individuals adopting more cynical attitudes. ${ }^{1}$ Based on these arguments, this paper poses the first hypothesis to be tested:

Hypothesis 1 The evaluative pressure perceived by an academic, stemming from performance measures and peer pressures, is positively related to him/her being more competitively oriented and having more cynical attitudes of his/her work context.

\section{The Relationship Between-Group Identification and Academics' Competitive Orientations and Cynical Attitudes}

Group identification is an interesting concept to focus on when explaining and understanding how subjects are incentivized and pushed toward orientations to compete rather than cooperate and what attitudes it creates about others in competitive social interactions. This section develops arguments for an independent effect of group identification on academics' competitive orientations and cynical views and, in a subsequent section, develop arguments for how it interacts with the evaluative pressures as per Hypothesis 1 .

As argued in the introduction, an evident effect of the managerial and accountingization development within the university sector is the increasing importance of the group as a unit of both competition and performance evaluation. Consistent with theories of teamwork, competition, and natural selection (DeChurch and Mesmer-Magnus 2010; Wade 1977; Wilson and Sober 1994; Stoelhorst and Richerson

\footnotetext{
1 To what extent a personal orientation precedes (causes) a change in how one views others (cynicism) or if they are simultaneous responses of evaluative pressures can be debated. At this stage of theory development and with the cross-sectional design employed, it suffices to argue that they are tightly related (go hand in hand) but different outcomes related to a self-interest orientation of evaluative pressures in academia. In the additional analysis section, the indirect effect of evaluative pressures on cynical attitudes, through a competitive orientation, is tested.
} 
2013) the group (a collective) level, as opposed to the individual level, tends to be beneficiary for the pursuit of individual and organizational (collective) goals when competing for scarce resources and when relative rather than absolute performance is the selector and performance criteria. When the performance of these groups becomes visible through different performance indicators, a kind of competitive market displaying the relative performance of these groupsfor example, a ranking or league table-(Northcott and Llewellyn 2003) is, or can be, created where groups can be compared. If competition is perceived as fierce, individuals within these groups tend to recognize or are forced by peers and management to recognize that joining with fellows is beneficial for the individual because it makes all better positioned in the between-group competition (Stoelhorst and Richerson 2013) that is the currency that translates into fame, legitimacy, and ultimately resources at the university. As such, the group, as opposed to the individual, gets more firmly established as an important unit of competition and evaluation that academic work (especially for publishing research and attracting funds) builds on. Also, more practical reasons for the group being prominent in academic work is that complex research tasks often require teamwork and teams to be effective (e.g., Bush and Hattery 1956).

Not all academics identify themselves strongly with a group despite being part of an informal or formal collective (e.g., group/department) and unit of evaluation and social comparison. However, with these developments and characteristics of the university sector as described above, there is likely a central tendency that academics at universities have adopted a stronger group-level mindset and identification (Ashforth and Mael 1989; Ellemers et al. 2002). Making it a relevant aspect to focus on.

In social psychology research and theories, a central notion is that interactions involving individuals emotionally and cognitively embedded in groups are generally more competitive and self-interest-oriented than person-to-personlevel interactions (Komorita and Parks 1995). When people strongly identify themselves as group members rather than just individuals (self), stereotypes of group interactions are evoked that foster distrust and fear toward "others", and within the group its members find social support for developing their self-interest, greed, and cynicism in the competition against "out-group members" (e.g., Schopler and Insko 1992; Pinter et al. 2007), i.e., for their wider social relations that expand beyond interactions with members from the group. It boils down to the view that a collective identification leads to "stereotypical perceptions of self and others" (Ashhfort and Mael 1989, p. 20) that affect social interactions. This is why people tend to show different, often more competitive and aggressive, behavior when interacting with a strong group-level identity as compared to the pure individual person-to-person level, a phenomenon labeled the interindividual-intergroup discontinuity effect (Wildschut et al. 2003).

The interindividual-intergroup discontinuity effect builds on at least four explanations as to why it is the case that interactions involving individuals with a strong group-level identity and mindset are more competitive than interindividual interactions (Pinter et al. 2007; Wildschut et al. 2003). The first explanation refers to the distrust, or fear, hypothesis. It concerns how the group-level mindset activates generalized beliefs (stereotypes) that groups are competitive and aggressive (Schopler and Insko 1992), making the interactive context of the individual more hostile. If competitive behaviors and orientations from others are anticipated, this affects one's interactive response reciprocally (Axelrod 1984), both in terms of choosing a competitive interactive strategy oneself and seeing others as driven by their self-interest (cynical attitude). A second explanation concerns that within groups, members give social support for self-interest-motivated choices in that they mutually reinforce each other's self-interest and greed (Wildschut et al. 2003), and thereby self-interest motivations of individuals in groups risk being cultivated, resulting in competitive interactive orientations and cynical attitudes about others. A third explanation is that with a stronger group-level mindset, and within the actual group, individuals may be sheltered from taking personal responsibility for competitive and aggressive actions taken. Individual actions become more anonymous, and blame is easier projected (either explicitly or implicitly when making personal sense of actions) at others in the group (Schopler et al. 1995). Such a mechanism makes it easier to choose and rationalize self-interest-motivated orientations and behaviors (in this article, to compete rather than cooperate and having cynical attitudes of others). Finally, a fourth explanation that has been forwarded is the presence of group norms and pressures for favoring and benefiting in-group members in collectives (Cohen et al. 2006). Implicitly, this also means a tendency toward disfavoring out-group members (Turner and Tajfel 1986; Jackson 1993) by, for example, constructing them as greedy, untrusting, and egoistic (i.e., holding cynical attitudes about them). So, in conjunction with this, there are quite compelling arguments backing up the general notion forwarded in this study that for academics who are embedded strongly within a group, their orientations are likely more self-interest driven compared to individuals who are weakly embedded within a group. In this article, such a seedbed for self-interest motivations to grow stronger is argued to influence and be manifested in how one views oneself as a competitor and how one views others as driven by their self-interest and ego (cynical attitudes).

While the psychology literature on the discontinuity effect often refers to group membership, it is not group membership per se that is the relevant concept; rather, it is the level of identification with, or embeddedness within, the 
group that explains the discontinuity effect (Schopler and Insko 1992). This is so because just to be organized into or voluntarily be a part of a group does not automatically make the individual adopt a strong identification with the group vis-à-vis the self (Ellemers et al. 2002). The group and discontinuity argument is that a strong identification with a group is the driver of discontinuities toward more selfinterest orientations for social interactions extending beyond the in-group. Individuals should have a sense of entitativity for the discontinuity hypothesis to be valid (Schopler and Insko 1992). Therefore, the individual's level of group identification becomes a relevant theoretical and empirical level of analysis in connection to the discontinuity hypothesis. Group identification, in this case, is about oneness with the group (or other types of collectives) (Ashforth and Mael 1989), and it is about the extent to which the individual's identity and the identity of the group overlap (Bartel 2001). The degree to which this is the case explains the likelihood that a discontinuity effect will emerge. This leads to the posing of the second hypothesis of this study:

Hypothesis 2 The individual's level of group identification is positively related to him/her being more competitively oriented and having more cynical attitudes of his/her work context.

\section{How do Group Identification and Evaluative Pressures Interact in Affecting Academics' Competitive Orientations and Cynical Attitudes?}

Although it is hypothesized that there are independent effects from both evaluative pressures and group identification on academics' competitive orientations and cynical attitudes, there are also compelling reasons to believe that they are (inter)dependent on each other. The first dependence between them relates to how group identification ought to strengthen the effect of evaluative pressures on academics' competitive orientations and cynical attitudes. The argument is that when such pressures relate to an individual with strong group identification, individual responses are more competitive and self-interest focused vis-à-vis individuals with weaker group identification. This is the reason why, from a psychological discontinuity perspective (e.g., Schopler and Insko 1992; Pinter et al. 2007), it is likely that a strong group identification cultivates academics' selfinterest-driven responses (competition and cynical attitudes) from evaluative pressures. This dependence might also work conversely: that the effect of group identification is strengthened by the level of evaluative pressure perceived by the individual. Since the discontinuity hypothesis builds on settings where competition and rivalry are present to some extent (a potential behavioral route) (Schopler and Insko 1992) if no or low(er) evaluative pressures are perceived by individuals (the context of the individual is less hostile/ competitive), the perceived between-group competition and interest conflicts are likely also less prevalent for the individual (Jackson 1993). Then, the mechanisms (e.g., social support for self-interest seeking and out-group/in-group dis/ favoring) explaining the competition and rivalry notion that is argued to be strengthened with strong group identification is likely less powerful. So, while there are good reasons to believe that perceived evaluative pressures and group identification are dependent on each other in affecting an individual's competitive orientation and cynical attitudes-an interaction effect is likely-to what extent this interaction/ dependence should be viewed as one of them being primarily a moderator or quasi-moderator (Sharma et al. 1981) for the other, or if they are truly interdependent (jointly reenforcing each other), is not possible to theoretically sort out in this case. Rather, this must be empirically evaluated/ established to contribute to theory development. This leads to the posing of a third, and final, hypothesis predicting their interaction:

Hypothesis 3 There is a positive interaction between perceived evaluative pressures and group identification on academics' competitive orientations and cynical attitudes of their work context.

\section{Method}

\section{Sample and Survey}

The empirical material builds on survey data and was included as a part of a larger survey about performance measurement in Swedish universities. ${ }^{2}$ The survey was submitted to people with permanent positions (lecturers and professors $^{3}$ ) at the 17 universities in Sweden. From a register handled by Statistics Sweden, addresses to a random sample of 2000 individuals (the sample frame included 13,250

\footnotetext{
${ }^{2}$ Much of the literature on evaluative pressures in universities is interpretative and explicitly acknowledges their lived experiences (autobiographic) as a source of inspiration for research (e.g., Gendron, 2008). While I mainly have had previous academic work as driving forces for the theoretical model, having deep knowledge about the sector and setting (being subject to evaluative pressures myself) has been very helpful in many ways, both when self-critically evaluating the theoretical model and when working with theoretical constructs and developing instruments in the survey. My experience of and amazement over seeing highly educated and otherwise very reflexive individuals (e.g., in their theory use) being taken over completely by evaluative regimes at universities have also contributed to my curiosity to work more deeply on this issue and to study its extent in the university sector in Sweden.

3 This means that all respondents have a Dr./Ph.D. degree.
} 
Table 1 Sample characteristics

\begin{tabular}{|c|c|c|c|c|c|c|}
\hline & $\%$ & & Mean/median & SD & Min & $\operatorname{Max}$ \\
\hline Scientific field: & & Age & $55.51 / 56$ & 9.73 & 23.0 & 82 \\
\hline Medicine and health & 18.9 & Research active & $3.7 / 4$ & 1.15 & 1.0 & 5 \\
\hline Social science (incl. law and business) & 26.6 & Position: & $\%$ & & & \\
\hline Natural science (incl. data science) & 17.7 & Professor (full or promoted) & 45.0 & & & \\
\hline Technical science/engineering & 9.0 & Senior lecturer (Docent) & 25.5 & & & \\
\hline Agriculture/veterinary medicine & 2.2 & Lecturer (Lektor) & 27.5 & & & \\
\hline Pedagogy/teacher training & 8.4 & Other & 2.0 & & & \\
\hline Humanities and art & 10.5 & & & & & \\
\hline Other & 6.7 & & & & & \\
\hline \multicolumn{7}{|l|}{ Sex: } \\
\hline Male & 58.8 & & & & & \\
\hline Female & 40.8 & & & & & \\
\hline Other/non-binary & 0.4 & & & & & \\
\hline
\end{tabular}

individuals) were acquired. The sampling was handled by Statistics Sweden. The questionnaire was sent out by postal mail in early 2019 and could be answered via both the web and a postal questionnaire. Versions in both Swedish and English (in cases of international faculty) were available. About $3.5 \%$ of the sample consisted of English answers. After two reminders, 756 questionnaires had been returned, resulting in a response rate of $38 \%$. This response rate is slightly (Franco-Santos and Doherty 2017; Kallio et al. 2016; Su and Baird 2017) and clearly (Chatelain-Ponroy et al. 2018) above previous similar research on academics, and it compares well with management accounting research in general (Hiebl and Richter 2018). Due to some (45) questionnaires being returned with mostly blank answers, the usable number of respondents in the dataset was 711. Item non-responses for the variables included in this research were generally few ( $\max 1.4 \%$ ), and an insignificant Little's MCAR test $(p=.149)$ showed that they appeared at random. For that reason, case-wise deletion (complete data matrix for the different models) was used in the PLS models (Hair et al. 2010).

In Table 1, descriptive statistics of the sample are shown. Comparing it to national statistics (www.uka.se), the distribution of sciences quite closely resembles population data, although the share of respondents from social science is a bit overrepresented in the sample. The data set is also a bit skewed in terms of the share of full professors. According to the same public statistics (in terms of the number of fulltime equivalents), the share of full professors to lectures is about $36 \%$. The median respondent is 56 years old and is highly research active. Since the current research is mainly about research performance and not teaching and administrative performance, the sample is regarded as both representative of research active permanent employees at Swedish universities and prototypical for the issue of testing hypotheses developed (Speklé and Widener 2018).

Several actions in the design of the survey and analyses of the data were taken to reduce the potential influence of common method variance (CMV) (Podsakoff et al. 2003). The respondents were promised anonymity and instructed that the interest was in their opinions, and thus that there were no right or wrong answers to the questions. Instead of posing all background questions (e.g., age, position, tenure, sex, etc.) as initial questions, these were placed as a "mental cleansing barrier" (emptying short-term memory and change focus in mindset) in between questions about the evaluative pressures and the outcome variables to create a psychological separation between constructs to reduce CMV (Podsakoff et al. 2003 , p. 888). The measure of one of the main variables in the study -group identification - was also deliberately made very differently from the other measures to reduce CMV (Podsakoff et al. 2003) (a graphical one-item measure compared to a traditional multi-item Likert scale). Since this study model interaction affects an important aspect of theory testing, CMV is of much less potential concern (Chang et al. 2010). Finally, using a latent variable (three items, see Appendix 2) of the intensity of use of library resources as a marker variable ${ }^{4}$ (Lindell and Whitley 2001), the highest shared variance of any relations with the marker variable was $2.6 \%$ (average shared variance $=.8 \%$ ), indicating that CMV is not an obvious threat to the study. Including the marker variable in the structural model (Table 3 below) does not lead to any substantial changes in hypothesized effects.

\footnotetext{
${ }^{4}$ On theoretical grounds, this variable is not apparently related to the other variables in the model but measured with a similar scale and format as most of the theoretical variables. For that reason, it is considered as an appropriate marker variable capturing response patterns caused by question formatting and respondent habits.
} 


\section{Measurements}

The competitive orientation of an individual was measured with two latent constructs capturing an individual orientation toward competitiveness and the view that a competitive system or environment affecting social interactions is desirable. The first construct concerns an individual orientation toward competitiveness (COMPET) and consists of three items. A sample item is: "It is important to me to do better than others". The second construct concerns the rivalry (RIVALRY) and the normative notion of competition, having the view that the system benefits from the competition (creative destruction, Schumpeter 1942). The construct is measured with two indicators. A sample item is: "Successful research builds on the fact that some are favored and others are disfavoured". Both these constructs build on items from a larger competition orientation construct developed by Simmons et al. (1988). To validate the notion that an individual sense of competitiveness and a normative view that competition is desirable is different/discriminant from the orientation to cooperate, COMPET and RIVALRY were correlated with four items capturing an individual's cooperative orientation (Simmons et al. 1988). All correlations show that an individual sense of competitiveness is inversely related to a cooperative orientation. The rivalry notion of competition is reversely related to all but one aspect of an individual cooperative orientation (see endnote for details). ${ }^{5}$ All in all, this confirms the important underlying assumption and claim of this study that COMPET and RIVALRY are contradictory to having a cooperative orientation.

Cynicism, or more correctly, cynical attitudes (Andersson 1996), is in this article about attitudes of individuals that "others" (peers, employers, etc.) are driven by their selfinterest. An individual's cynical attitudes of his/her work context were measured with two different latent constructs. The first construct consisted of three items building on Turner and Valentines' (2001) general cynicism scale capturing to what extent others are seen as driven by self-interest. A sample item is: "When someone does me a favor at work, I know they expect one in return", and the construct is labeled cynicism (CYNICISM). The second construct concerns the notion that cynical attitude is about having a view

\footnotetext{
${ }^{5}$ COMPET/RIVALRY was correlated with the following: "It makes me happy when other researchers whom I know in the field are successful, since it brings research within the field forward" $(r=-0.164$; $p<0.01 / r=-0.076 ; p<0.05$ ), "I gladly share knowledge and ideas with researchers from other groups and universities that I meet" $(r=-0.259 ; \quad p<0.01 / r=-0.093 ; \quad p<0.05)$, "Cooperation across group- and organizational borders is the best way to be successful within one's own research" $(r=-0.159 ; p<0.01 / 0.031 ; p>0.1)$, and "At the end of the day, openness toward researchers from other groups is not compatible with success for one's own research group" $(r=0.830 ; p<0.01 / r=0.217 ; p<0.01)$
}

on scientific practices as (partially) corrupt, that "others" do whatever it takes to be successful/publish, and consists of two items. A sample item is: "I believe that some researchers stretch the truth to get their research published", and the construct is labeled corrupt (CORRUPT).

As argued in the theory section, evaluative pressures stem from both performance measurement systems and peer pressures, and these aspects are captured with two different constructs. The first construct concerns the perceived emphasis and importance put on quantitative indicators (such as the number of publications and citations, and different rankings of publication output) for promotions (docent and professor), recruitment, granting of internal university funding (e.g., for research time), and salary. The construct is labeled performance measure emphasis (PME) and is a somewhat adapted (for face validity reasons, Kwok and Sharp 1998) version of a construct used by Vogel and Hattke (2018). The evaluative pressure exerted by peers is measured with a construct that builds on the conceptualization and measurement developments done by De Jong et al. (2014) and with guidance from how peer pressure was conceived in the Ter Bogt and Scapens (2012) study (a form of the publish-or-perish norm). It is a latent variable consisting of four items (see Appendix 2). Two sample items are: "We openly express our dissatisfaction with colleagues who do not follow the group norms", and "If a colleague does not live up to the established research norm, it is not unusual that s/he quits or engages in administrative or teaching activities". The construct is labeled as peer pressure (PP).

Group identification (Gident) was measured with a graphical tool/instrument used to capture organizational identification in previous research (Bergami and Bagozzi 2000; Bartel 2001). It intends to measure the "cognitive organizational identification (self-categorization) as the perceived overlap between one's own self-concept and the identity of the organization" (Bergami and Bagozzi 2000, pp. 555-556). The respondents were instructed to rate how close their own researcher identity and the identity of the group overlap by marking closer and closer overlapping ellipses (see Appendix 2). They were instructed to think about the "group" (research group, lab-team, department, institute, etc.) they feel most committed to when answering the question. The measure ranges from 1, far apart, to 8 , complete overlap. To validate the discrimination from identification with other collectives (multiple identities), group identification was correlated with items asking for the felt importance of affiliation with the scientific field $(r=.143$; $p<.01)$, research group $(r=.476 ; p<.01)$, department/ school $(r=.245 ; p<.01)$, and university $(r=.088 ; p<.05)$. As shown by these correlations, the research group and also the department that might be the distinct group of interestsee above-stands out as the most important affiliation for respondents with high group identification. Additionally, to 
validate the notion that group identification in this context does not also relate to within-group rivalry and competition but rather to interactions in their wider social relations in the scientific community, items asking to what degree the respondents feel that they are competing with colleagues within their "group", individuals from other "groups" at the university, and with individuals from other universities were correlated with group identification. The level of group identification was negatively correlated $(r=-.142 ; p<.01)$ with the within-group competition, unrelated to individuals from other departments within the university, and positively related $(r=.090 ; p<.05)$ to individuals from other universities, indicating that the hypothesized relation to a competitive orientation relates to the wider social relations rather than to cannibalism within the group.

\section{Control Variables}

Several control variables are used. To control for potentially different organizational cultures and other particularities within the different universities (potentially omitted variables) that the individual responses come from, University is included as a fixed effect control ( $N-1$ dummy variables). Respondent sex (male vs. female and other) is included with the argument that previous research has found males to on average be more competitive and cynical than females (e.g., Leung et al. 2012). Experience (measured as years in academia: 1-4, 5-9, 10-19, 20-29, 30- years) (EXPERIENCE) might be a factor that affects how an individual perceives and responds to evaluative pressures. The effect can potentially go both ways. Less experienced individuals might perceive the evaluations as harsher than more experienced individuals (they have not yet learned to effectively "cope with the system"), or less experienced individuals might be more accustomed to (they are born into the system) the managerial and performance-oriented turn within academia which has normalized such practices. Although all respondents are drawn from a register of permanent faculty, academic rank and position might still be influential. In Sweden, it is not the practice that one loses one's employment and rank because of research "underperformance". But for junior academics that strive for an academic carrier, complying with norms and standards of high research performance is important. Then such individuals may feel more exposed to and threatened by evaluative practices that potentially affect their perceptions of and responses from evaluative practices. The variable position (POSITION) compares full professors to others (lectures and senior lectures; the latter is in Sweden termed Docent). As an interaction control variable, analyzed in the additional analysis section, the respondent's self-rated performance (number of publications, quality of publications, and external funding compared to peers at a similar rank/position) is included, the reason being that it is not unlikely that the effect of evaluative pressures on the forming of cynical attitudes is less pronounced for individuals that feel successful in terms of research output and research funding.

\section{Analysis Strategy}

Component-based (PLS) structural equation modeling is chosen as the statistical method to test hypotheses, a statistical method well utilized within accounting research as well as business ethics research (e.g., Goebel and Weißenberger 2017). There are several reasons for the use of PLS-SEM rather than, for example, covariance-based SEM. First, the measures used for this research task are of an explorative and novel nature. Although the measures have been designed with close inspiration from previous instruments dealing with the theoretical rationale of the constructs, they have been tailored and developed for the specific research task and have thus not been validated before. Second, because most of the latent constructs only have two or three indicators, ${ }^{6}$ confirmatory, or common, factor analysis is not informative because such models need four indicators to be over-identified (Kline 2011) to be able to get model fit statistics assessing construct validity beyond mere rules of thumb. Furthermore, the use of latent variables with fewer than three indicators in CFAs is often unreliable (Hair et al. 2010). Third, the modeling of latent variable interactions is a very complicated and contested issue within covariancebased SEM (e.g., Jöreskog and Yang 1996). Since this study will test and explore up to eight latent variable interactions (one per DV for PME and PP), component-based SEM, being less assumption conservative, is the realistic option. The drawback of using component-based SEM for this research task is that the issue of measurement error is not handled as effectively as had been the case with covariancebased SEM. However, as has been shown in simulation studies, the difference in this respect tends to be modest (Sarstedt et al. 2016).

\section{Measurement Properties}

All latent constructs were evaluated for convergent and discriminant validity. A first analysis revealed that oneitem adhering to the CYNICISM construct loaded below 0.7 (0.636) and lowered the average of loadings, resulting in an AVE $<.5$. The second item from that construct was thus deleted (see Appendix 2 for a full description of the

\footnotetext{
${ }^{6}$ The constructs used for this research were part of a wider survey on academics' attitudes toward performance measurement and evaluation. Because of that, space limitations (survey length) did not allow for the inclusion of extensive multi-item instruments connected to this particular research question/project.
} 
Table 2 Measurement properties

\begin{tabular}{|c|c|c|c|c|c|c|c|c|}
\hline & $\mathrm{CR}$ & AVE & Loading & $\operatorname{Min} / \max$ & Mean & SD & Kurtosis & Skewness \\
\hline COMPET & 0.886 & 0.796 & & $1 / 5$ & 2.336 & 1.033 & -0.686 & 0.357 \\
\hline Item 1 & & & 0.905 & & & & & \\
\hline Item 2 & & & 0.879 & & & & & \\
\hline Rivalry & 0.801 & 0.668 & & $1 / 5$ & 2.026 & 0.946 & 0.233 & 0.846 \\
\hline Item 1 & & & 0.825 & & & & & \\
\hline Item 2 & & & 0.809 & & & & & \\
\hline CYNICISM & 0.770 & 0.626 & & $1 / 5$ & 2.457 & 0.885 & -0.139 & 0.374 \\
\hline Item 1 & & & 0.738 & & & & & \\
\hline Item 2 & & & 0.842 & & & & & \\
\hline CORRUPT & 0.826 & 0.704 & & $1 / 5$ & 2.887 & 0.989 & -0.496 & 0.274 \\
\hline Item 1 & & & 0.892 & & & & & \\
\hline Item 2 & & & 0.782 & & & & & \\
\hline PME & 0.860 & 0.607 & & $1 / 5$ & 3.463 & 0.914 & -0.118 & -0.536 \\
\hline Item 1 & & & 0.837 & & & & & \\
\hline Item 2 & & & 0.818 & & & & & \\
\hline Item 3 & & & 0.706 & & & & & \\
\hline Item 4 & & & 0.749 & & & & & \\
\hline PP & 0.822 & 0.535 & & $1 / 5$ & 2.539 & 0.849 & -0.025 & 0.378 \\
\hline Item 1 & & & 0.685 & & & & & \\
\hline Item 2 & & & 0.740 & & & & & \\
\hline Item 3 & & & 0.746 & & & & & \\
\hline Item 4 & & & 0.754 & & & & & \\
\hline Self-rated perf & 0.829 & 0.618 & & $1 / 5$ & 3.076 & 0.753 & -0.142 & -0.037 \\
\hline Item 1 & & & 0.859 & & & & & \\
\hline Item 2 & & & 0.751 & & & & & \\
\hline Item 3 & & & 0.744 & & & & & \\
\hline Gident & & & & $1 / 8$ & 4.757 & 1.848 & -0.524 & -0.360 \\
\hline Male & & & & $0 / 1$ & 0.588 & & & \\
\hline Experience & & & & $1 / 5$ & 3.426 & 1.007 & -0.379 & -0.150 \\
\hline Position & & & & $0 / 1$ & 0.450 & & & \\
\hline
\end{tabular}

instrument used). In Table 2, the revised measurement shows that all latent variables have composite reliability $(\mathrm{CR})$ above 0.7 and average variance extracted (AVE) above 0.5, which shows that they are highly reflective (uni-dimensional) in nature. Discriminant validity was first assessed by looking at the correlations per se and comparing the square root of the AVE with variable correlations (see Appendix 1). Correlations are not excessive, and all correlations are clearly below a construct's squared AVE (Fornell and Larcker 1981). Second, discriminant validity was also assessed with the heterotrait-monotrait ratio. The highest value was 0.665 , which is clearly below the suggested 0.9 cutoff (Henseler et al. 2015), implying satisfactory discriminant validity. All loadings/ weights were highly significant $(p<.01)$ using bootstrapping with 5,000 re-samples.

\section{Results}

\section{Hypothesis Tests}

In Table 3, three different PLS path models are shown. The first model (Panel A) concerns Hypotheses 1 and 2, estimating independent (direct) effects of evaluative pressures (PME and PP) and group identity (Gident). The second model (Panel B) concerns one part of Hypothesis 3, in which the interaction between PME and group identity is estimated. In a third model (Panel C), the interaction between PP and group identity is estimated. ${ }^{7}$ In the final analysis, conditional

\footnotetext{
$\overline{7}$ The reason for separating the testing of the interactions (H3) in two models is model complexity. Estimating eight interactions all involving group identity risks creating severe multicollinearity and overfitting (and thus power) problems.
} 
Table 3 PLS path models

\begin{tabular}{|c|c|c|c|c|}
\hline From/to & COMPET & RIVALRY & CYNICISM & CORRUPT \\
\hline \multicolumn{5}{|l|}{ Panel A: direct effects } \\
\hline PME & -0.044 & $0.071^{*}$ & 0.016 & -0.067 \\
\hline PP & $0.093 * *$ & $0.186 * * *$ & $0.351 * * *$ & $0.323 * * *$ \\
\hline Gident & $0.150 * * *$ & -0.055 & -0.028 & -0.057 \\
\hline MALE & $0.109 * * *$ & 0.001 & $0.094 * *$ & $0.172 * * *$ \\
\hline EXPERIENCE & -0.036 & $0.104 * *$ & $-0.075^{*}$ & -0.053 \\
\hline POSITION & $0.168 * * *$ & -0.027 & -0.053 & -0.066 \\
\hline University fixed effects & YES & YES & YES & YES \\
\hline$R^{2}$ & 0.131 & 0.077 & 0.159 & 0.14 \\
\hline \multicolumn{5}{|l|}{ Residual correlations } \\
\hline RIVALRY & $0.120 * * *$ & & & \\
\hline CYNICISM & $0.115 * * *$ & $0.203 * * *$ & & \\
\hline CORRUPT & $0.085 * *$ & $0.111 * * *$ & $0.199 * * *$ & \\
\hline \multicolumn{5}{|l|}{$N=675$} \\
\hline \multicolumn{5}{|c|}{ Panel B: PME $\times$ Gident interaction effects } \\
\hline \multicolumn{5}{|l|}{ Main effects } \\
\hline PME & 0.018 & $0.152 * * *$ & $0.129 * *$ & 0.041 \\
\hline Gident & $0.133 * * *$ & -0.071 & -0.071 & $-0.089 * *$ \\
\hline \multicolumn{5}{|l|}{ Interaction effects } \\
\hline PME $\times$ Gident & $0.089 * * *$ & 0.031 & -0.005 & 0.029 \\
\hline \multicolumn{5}{|l|}{ Control variables } \\
\hline MALE & $0.108 * * *$ & -0.016 & $0.088 * *$ & $0.171 * * *$ \\
\hline EXPERIENCE & -0.043 & $0.107 * * *$ & -0.053 & -0.037 \\
\hline POSITION & $0.172 * * *$ & -0.030 & -0.060 & -0.053 \\
\hline University fixed effects & YES & YES & YES & YES \\
\hline$R^{2}$ & 0.131 & 0.053 & 0.063 & 0.052 \\
\hline \multicolumn{5}{|l|}{$N=683$} \\
\hline \multicolumn{5}{|c|}{ Panel C: PP $\times$ Gident interaction effect } \\
\hline \multicolumn{5}{|l|}{ Main effects } \\
\hline PP & $0.091 * *$ & $0.219 * * *$ & $0.347 * * *$ & $0.309 * * *$ \\
\hline Gident & $0.119 * * *$ & -0.06 & -0.028 & $-0.075^{*}$ \\
\hline \multicolumn{5}{|l|}{ Interaction effects } \\
\hline $\mathrm{PP} \times$ Gident & $0.188 * * *$ & $0.075^{*}$ & -0.033 & $0.059^{*}$ \\
\hline \multicolumn{5}{|l|}{ Control variables } \\
\hline MALE & $0.122 * * *$ & -0.008 & $0.084 * *$ & $0.180 * * *$ \\
\hline EXPERIENCE & -0.052 & $0.096^{* *}$ & $-0.084 * *$ & -0.051 \\
\hline POSITION & $0.174 * * *$ & -0.041 & -0.046 & -0.061 \\
\hline University fixed effects & YES & YES & YES & YES \\
\hline$R^{2}$ & 0.137 & 0.077 & 0.159 & 0.138 \\
\hline$N=683$ & & & & \\
\hline
\end{tabular}

Std. PLS coefficients and residual correlations (panel A) shown; two-tailed BCa bootstrap with 5000 resamples; residual correlation significance is assessed with $t$-test statistics

${ }^{*} p<0.1$; sig. ${ }^{* *} p<0.05$ sig.; $* * * p<0.01$ sig. (two-tailed)

effects (simple slopes) are presented in order to further interpret and visualize the interactions.

In Panel $\mathrm{A}$ in Table 3 , it is shown that PP affects all dependent variables positively and statistically significant $(p<.1)$. The effect is weakest on COMPET $(B 0.093$, $p<.05)$, somewhat stronger on RIVALRY $(B 0.186, p<.01)$, and strongest on CYNICISM $(B$ 0.351, $p<.01)$ and CORRUPT $(B 0.323, p<.01)$. Regarding the effects from PME, it is only in the instance of RIVALRY that there is a positive and statistically significant $(B 0.071, p<.1)$ effect in accordance with Hypothesis 1. In sum, Hypothesis 1 


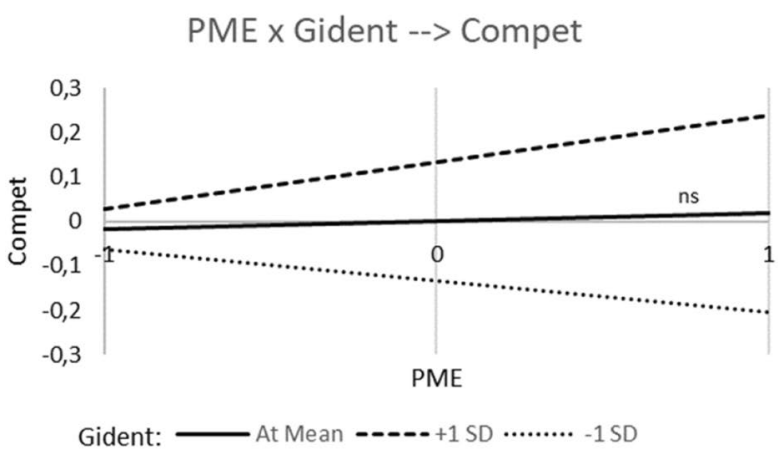

Note: $n s$ means not significant ( $p>0.05)$.

Fig. 2 Simple slope plots for PME $\times$ Gident interaction (panel B, Table 3)

is corroborated strongly by the effects of peer pressure, but only partially by the effects of performance measure emphasis.

Concerning Hypothesis 2, Panel A further contains information about the effect of group identity on the dependent variables. Group identity positively and significantly $(B$ $0.150, p<.01)$ affects COMPET, but not the other dependent variables. Hypothesis 2, about an independent effect of group identity on individuals' competitive orientations and cynical attitudes, is thus only partially corroborated. The control variables show that males, compared to females, on average are more competitive and hold more cynical attitudes, that experience is positively related to RIVALRY and negatively related to CYNISM, and that professors (versus others-POSITION) score higher on COMPET. In Panel $\mathrm{A}$, (inner) model residual correlations are disclosed to show that all four dependent variables relating to an individual's competitive orientations and cynical attitudes are jointly determined, that is, they are positively related in the sense that movement (an increase) in one is related to a symmetrical movement (a central tendency) in the others. As theorized, they all relate symmetrically to the higher-order concept of a self-interest orientation. Although positively related, the correlations are not excessive, which means that they also are separate responses.

In Panels B and C, interaction effects following Hypothesis 3 are estimated. In Panel B, it is shown that there is a positive and statistically significant interaction effect between PME and Gident $(B 0.089, p<.01)$ on COMPET, but not on the other three dependent variables. In Panel C, the interaction between PP and Gident is estimated. The interaction effect is supportive for three out of the four dependent variables. The effect is strongest for COMPET $(B 0.188, p<.01)$ and somewhat weaker for RIVALRY $(B 0.075, p<.1)$ and CORRUPT $(B 0.059, p<.1)$. In that sense, Hypothesis 3 gains considerable support in that group identity, and the two sources of evaluative pressures positively interact in affecting especially an individual's competitive orientation, but also their cynical attitudes (corrupt). As with Hypothesis 1 , the effects are more apparent for peer pressure than for performance evaluation emphasis.

To further interpret the interactions and explore if and to what extent they jointly reinforce each other, simple slope plots of conditional effects at -1 (low), the mean, and +1 (high) standard deviation of the "moderator/interactor" are shown in Figs. 1 (panel B) and 2 (panel C). The plots show conditional effects of changing the "moderator/interactor" being the conditioner to assess how, for example, the effect of PME on COMPET is altered by Gident and how the effect of Gident on COMPET is altered by PME, respectively. Figure 1 shows that both the effects of PME and Gident on COMPET are strengthened by the other; that is, they jointly re-enforce each other. At high levels of Gident (left-hand side of Fig. 1), the effect of PME is positive, and at low levels, it is even negative. For the effect of Gident on COMPET (right-hand side of Fig. 1), the effect is more positive for higher levels of PME.

Figure 2 shows that the pattern of a jointly re-enforcing effect is visible also for the interaction between PP and Gident on COMPET (upper part of Fig. 2). For the significant interactions between PP and Gident on RIVALRY and CORRUPT, Fig. 2 reveals that they are not jointly re-enforcing each other. Although they both depend on each other, as shown by the significant interaction term in Panel C in Table 3, Fig. 2 shows that it is the moderation by Gident for the effects of PP that works in a manner supporting Hypothesis 3. The effect of PP on RIVALRY and CORRUPT is stronger (steeper/more positive) for higher values of Gident. This is not the case, however, with how PP moderates the effect of Gident. Rather, it seems that the effect of Gident is weakly negative when PP is low. Although this finding goes against Hypotheses 2 and 3, it is still interesting to note that this weak negative effect is canceled out at higher levels of PP. In sum, it can be concluded that for an individual's 

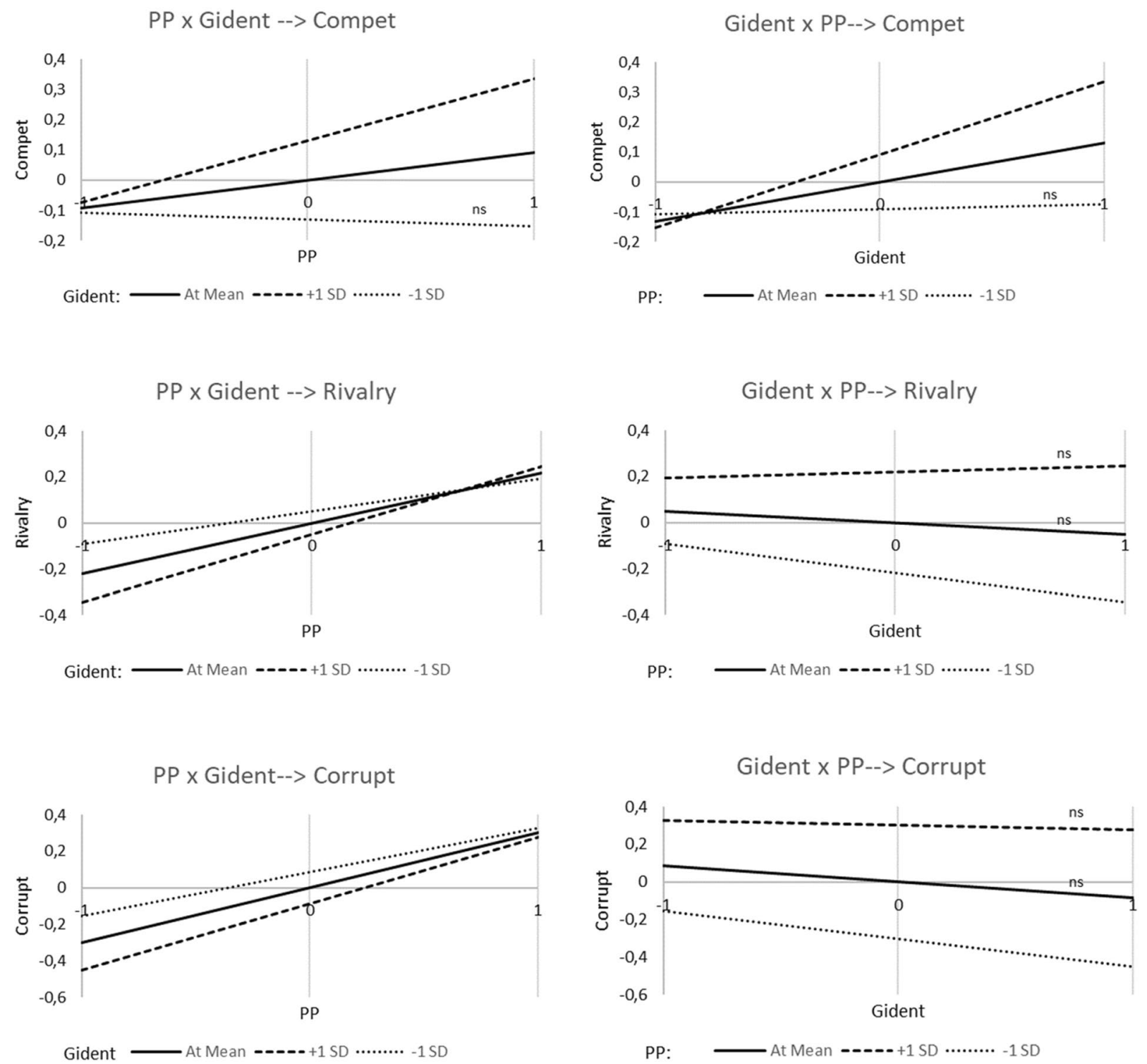

Note: $n s$ means not significant $(p>0.05)$.

Fig. 3 Simple slope plots for $\mathrm{PP} \times$ Gident interactions (panel C, Table 3)

competitive orientation, both PME and PP on the one hand and Gident on the other jointly re-enforce each other. For the outcomes in the form of RIVALRY and CORRUPT, theorizing is supported by Gident, strengthening (being a moderator for) the positive effect of PP (Fig. 3).

\section{Additional Analyses and Robustness Checks}

As explained in the method section (control variables), selfrated performance was included as an interaction control between PME, PP, and Gident on the dependent variables. No significant interaction effects resulted, meaning that the hypothesized effects (H1-2) do not depend on whether individuals regard themself as successful or not. It is notable, though, that there exist positive direct/main effects on both COMPET and RIVALRY from the self-rated performance variable (see also correlation matrix in Appendix 1). Controlling for self-rated performance did not affect the NHST in Table 3 (H1-3).

Parts of the arguments for why cynical attitudes go hand in hand with an increased competitive (self-interest) orientation might imply that it is a competitive orientation that precedes/causes cynical attitudes rather than cynical attitudes being a simultaneous outcome of evaluative pressures. 
Although such cause-and-effect analyses require crosslagged models and longitudinal data, an indirect/mediation effect model was also assessed (PME/PP $\rightarrow$ COMPET/ RIVALRY $\rightarrow$ CYNICISM/CORRUPT) to shed some light on this issue. Weak but statistically significant $(p<.1)$ indirect effects resulted for PP, RIVALRY, CORRUPT, and PME/ PP, RIVALRY, CYNSIM, but the mediation model did not suppress the direct effects as per panel A in Table 3. Indirect effects from Gident were not found. So, while some indirect effects appear, the influence of the direct effects from PME and PP on CYNICISM and CORRUPT is the most notable, which speaks in favor of the view that the altered personal orientation simultaneously changes the perspectives of others.

Although the measurement model issue (number of items per latent variable and the early stage of measure development) and the issue of estimating several simultaneous latent variable interactions effects speaks against the use of common factor analysis and covariance-based SEM, the direct effect model as per Panel A in Table 3 was estimated with such software as a robustness check. ${ }^{8}$ The replication shows somewhat stronger paths (higher std. beta) from the independent latent variables in the form of PME and PP, but very similar effects from the manifest variables (Gident and the control variables), a logical result considering that unexplained variance at the sub-equation level is modeled. In the case of the effects of PME, it also renders different results in that the negative effects (still weak) on COMPET $(p<.1)$ and CORRUPT $(p<.01)$ become statistically significant. In sum, for the hypothesis test (NHST) of Hypotheses 1 and 2 , the use of component-based or covariance-based SEM leads to the same conclusion. For the prediction versus testing debate of PLS-SEM (e.g., Rönkkö and Everman 2013), regression models (OLS) with variables made up of factor scores (PCA) of items were estimated. These models replicated the results in Table 3 substantially identically.

\section{Conclusions and Contributions}

Departing from and problematizing the increasing accountingization of academia, the rationale of this article is to study if evaluative pressures in universities (e.g., Ter Bogt

\footnotetext{
8 Two constraints were imposed on the measurement model. All paths from indicators to the dependent/exogenous latent variables were constrained to be equal, and hence the variance fixed to 1 . This was done to make the under-identified latent factor structures more stable. Model fit statistics were as follows: X2 688.435; Df 289; CFI 0.909; RMSEA 0.044 (pclose 0.989). It should be noted that in some instances in this model, factor loadings of the constructs were too low to show evidence of convergent validity. Therefore, the structural model results using covariance-based SEM should be viewed with caution. This supports using PLS-SEM as the main method.
}

and Scapens 2012) and identification with collectives (e.g., Ashforth 2016) cultivate academics' self-interest orientations for their social relations in the science community. This makes them adopt competitive orientations and cynical attitudes, aspects of an individual's orientation and attitudes that are trajectories and evidence of an egoistic and cynical ethical climate (Victor and Cullen 1988; Turner and Valentine 2001). The position of this article is that cultivating the self-interest of academics may not be an unethical act per se by research leaders at universities. It is, however, utterly important to be aware of the unethical attitudes and consequences it potentially gives rise to (Kish-Gephart et al. 2014) and when it for example means the adoption of a competitive orientation at the expense of a cooperative orientation and the development of cynical attitudes about peers and the work environment (Turner and Valentine 2001; Vice 2011). Matters that raise ethical concerns about the viability of the increasing managerialism and evaluative turn within academia.

At a general level, the results of this article show that evaluative pressures and group identification, either independently or interactively, are related to individuals having more of a competitive orientation that importantly also means less of a cooperative orientation and to them having more of cynical attitudes about peers and their work environment. To the best of my knowledge, large-scale evidence across science disciplines and universities of relations between evaluative pressures and such altered orientations and attitudes is scant, and the present study thus contributes to knowledge and empirical awareness of the consequences of the managerial and evaluative turn in academia (e.g., Parker 2011, 2013; Ter Bogt and Scapens 2012; Gendron 2015; Kallio et al. 2016). More specifically, the current study contributes by showing that the perceived evaluative pressure from the use of quantitative performance measures is not the factor that primarily accounts for the link between evaluative pressures and competitive orientation and cynical attitudes among academics. Instead, it is primarily the evaluative pressure to perform and conform exerted by peers that is influential. These results extend the finding by Ter Bogt and Scapens (2012), which indicated that peer pressure was very influential in one of their case organizations. That peer pressure-a form of peer control (Loughry 2010) - is influential is not surprising, considering the characteristics of academia. What is noteworthy is that this study shows that the change in administrative structures (formal performance evaluation) has become embedded in publish-or-perish norms among peers and that it is peer norms in universities that probably is the factor to try to govern to reduce overly competitive orientations and cynical attitudes to emerge. The importance of peer control also contributes to management control ethics research more generally (Falkenberg and Herremans 1995; Goebel and Weißenberger 2017) by pointing to the 
importance of another type of informal and social control mechanism-peer control-influential for ethical issues in organizations. This study, thus, cumulatively adds to the research by pointing to the importance of informal/social types of controls for organizational ethics research. While Goebel and Weißenberger (2017) show how social controls can work to create an ethical culture (Treviño et al. 2014) cultivating ethical awareness, this study instead points to the darker ethical side of informal and social controls. An implication is that it is not informal control per se but the content of and context around it that determines the type of ethical climate and orientations for individuals they give rise to.

It is also noteworthy that the effect from perceived evaluative pressures (peer pressure primarily) is most salient for expressing cynical attitudes, which is most likely not a mindset of individuals that academia and the practice of doing research will benefit from in the long term. Being cynical about the motives of other academics and the work environment signals frustration, hopelessness, and disillusionment among individuals, and has been associated with unethical behavior in organizations (Andersson 1996). Having cynical attitudes has also been argued to be immoral per se because of the immoral perspective being projected at others (Vice 2011). These results, thus, contribute to the growing literature on the ethical and motivational drawbacks of performance cultures and evaluative pressures for academics and academic work (e.g., Kallio et al. 2016; Franco-Santos and Doherty 2017; Vesty et al. 2018; Chatelain-Ponroy et al. 2018). A more general conclusion concerning the issue of performance measure and evaluation in academia is, thus, that while evaluative pressures seem to make individuals adopt somewhat more competitive orientations that might be regarded as an intended effect from control designers in universities, such orientations also go together with academics being less cooperatively oriented and adopting cynical attitudes about their work environment. That the cultivation of self-interest and competition in organizations seems to go hand in hand with viewing upon others as driven by their self-interest (cynicism) clearly adds a previously undiscussed and unnoted ethical dimension to evaluative pressures in organizations (Vice 2011). To what extent the net effect (competition minus cynicism) will be mainly positive or negative for academia thus becomes an ethical, as well as instrumental, question that constitutes a practical implication for managers and research leaders at universities to reflect upon.

As argued in the article, for the accountingization debate in academia and business ethics research more generally (e.g., Treviño et al. 2014), combining research on the effects of evaluative pressures with group identification is important because of the increased emphasis (by accounting) put on groups at universities and the territorializing role of accounting (Miller and Power 2013). This is so because it is likely to expect that group identification has an additional cultivating effect of individuals' self-interest that translates into competitive orientations and cynical attitudes. Notably, the results of this article only lend partial support to group identification having an independent (main) effect on academics' competitive orientations and cynical attitudes. It is for the notion of a personal sense of competitiveness that group identification is influential, but not for their rivalry notions and cynical attitudes; rather, it is in interaction with evaluative pressures that group identification becomes influential. Shown and supporting this notion is that the effect of group identification on an individual's competitiveness is strengthened by the level of perceived evaluative pressure (both from the quantitative measures and peer pressure) exerted on the individual. When evaluative pressures are low, group identification is uninfluential. In this instance, it should be noted that the interaction between group identification and evaluative pressures is one where they jointly re-enforce each other. The level of group identification strengthens the effect of evaluative pressures on an individual's sense of competitiveness. The role of group identification is of utter importance because when such identification is low, evaluative pressures do not lead to individuals adopting a more competitive selfimage. Group identification, in this case, sets a boundary condition for when the hypothesis that evaluative pressures affect individuals in being more competitively oriented is valid. The role that group identification plays for such relations has not been accounted for in previous research on performance evaluation in academia and points to the importance of this issue to better understand how the managerial and accountingization turn in academia affects academics' competitive orientations and self-image.

While being a joint re-enforcer for an individual's sense of competitiveness, theorizing on the interaction between group identification and evaluative pressures is further corroborated by group identification moderating (strengthening) the relationships between peer (evaluative) pressure and an individual's notions of rivalry and of research being a corrupt business. This differing between group identification working as a joint re-enforcer with, or a moderator of, evaluative pressures for different outcomes related to an individual's self-interest orientation further details the role of group identification in explaining individuals' competitive orientations and cynical attitudes. Future research should theorize and test under which circumstances the one or the other model is most likely. From the results of this article, one such possible theoretical dimension could be the difference between how one views oneself (joint re-enforcer) and how one views others (moderator). These results on the interactions between evaluative pressures and group identification give important implications for research on organizational ethics more generally, where research on how groups and commitment (identification) to them affects (un)ethical 
behavior in organizations have been called for (Treviño et al. 2014). Group identification might be an important moderator/interactor to include in ethics research dealing with the cultivation of self-interest and the development and consequences of egoistic ethical climates in organizations more generally.

\section{Limitations and Directions for Future Research}

As with all studies, this research is not without its limitations, and there are several possibilities for future research to extend and deepen the results of this study. The measures used for the dependent variables are novel in this context. Although they all show adequate psychometric properties, the measures could be extended with more items on the same theme to make more robust assessments (CFA) of the measurement model possible. With the cross-sectional design, empirical causality cannot be established, and future longitudinal research capturing change in competitive orientations and cynical attitudes is a way forward. However, at this stage of development, the level of evaluative pressures might be significant and widespread, making it harder to find variation over time for individuals. This makes the current approach of recording cross-sectional variation in perceptions between individuals more relevant. Controlling for fixed effects of the university is likely an effective approach to control for many hard-to-measure and unobservable omitted variables. Common method bias/variance is a concern when utilizing common source data. With the design steps taken and the statistical approaches used (marker variable and interaction effects), these concerns are not an obvious threat, but they cannot be excluded in total.

The national context of Sweden means a context where managerialism, competition, and formal and informal performance evaluation is widespread (e.g., Englund and Gerdin 2020) and as such it shares features with many other countries and settings where similar research has been conducted. Still, certain differences in employment structures, the legal status of universities, and cultures between countries might be factors that warrant some caution when it comes to empirical generalizations. It is also important to remember that there are national settings where the managerial turn has not yet affected university practices and cultures toward promoting for example "international publications" as the only means for status, power, and legitimacy (see e.g., Albu and Albu 2015, on the developments in East Europe), which also sets limits for the generalizability of the current findings. Cross-country comparative research is needed to shed further light on these issues.
Although it is cynical attitudes that are in focus and not a skeptical disposition or alike, such dispositions may nevertheless be important because they can be relevant moderators for the link between evaluative pressures and cynical attitudes (Andersson 1996). To further explore how, for example, individuals high or low on Machiavellianism respond to such pressures could make stronger and weaker associations in different subgroups visible and contribute to a more detailed and nuanced understanding of how evaluative pressures in universities relate to the cultivation of self-interest-related orientations and attitudes. Related to this issue, it seems relevant to explore other design and use aspects of evaluation systems in universities to create knowledge of how to potentially minimize cynical attitudes and non-cooperative orientations to emerge because of evaluative pressures. The critical and utterly ethical question is if control designers can induce competitiveness without it also leading to potentially problematic effects for researchers' identities and academic practices at large. The results of this study point to the importance of continued research on the attitudinal as well as behavioral consequences of performance evaluation pressures in universities.

Acknowledgements I would like to thank the two reviewers for their constructive comments and suggestions. The article has also benefitted from comments at seminars at the Stockholm School of Business and Economics and the Vienna University of Economics and Business. Special thanks to Monika Berg and Sven Siverbo for closely reading comments of earlier versions.

Funding Open access funding provided by Örebro University. The research was funded by the Swedish Research Council (no 421-2014-740).

Open Access This article is licensed under a Creative Commons Attribution 4.0 International License, which permits use, sharing, adaptation, distribution and reproduction in any medium or format, as long as you give appropriate credit to the original author(s) and the source, provide a link to the Creative Commons licence, and indicate if changes were made. The images or other third party material in this article are included in the article's Creative Commons licence, unless indicated otherwise in a credit line to the material. If material is not included in the article's Creative Commons licence and your intended use is not permitted by statutory regulation or exceeds the permitted use, you will need to obtain permission directly from the copyright holder. To view a copy of this licence, visit http://creativecommons.org/licenses/by/4.0/.

\section{Appendix 1}

See Table 4. 
Table 4 Correlation matrix

\begin{tabular}{|c|c|c|c|c|c|c|c|c|c|c|c|}
\hline & 1 & 2 & 3 & 4 & 5 & 6 & 7 & 8 & 9 & 10 & 11 \\
\hline 1. COMPET & 0.877 & & & & & & & & & & \\
\hline 2. RIVALRY & $0.120 * *$ & 0.829 & & & & & & & & & \\
\hline 3. CYNICISM & $0.127 * *$ & $0.267 * *$ & 0.791 & & & & & & & & \\
\hline 4. CORRUPT & $0.097 *$ & $0.137 * *$ & $0.280 * *$ & 0.839 & & & & & & & \\
\hline 5. PME & -0.012 & $0.135 * *$ & $0.134 * *$ & 0.004 & 0.779 & & & & & & \\
\hline 6. PP & 0.070 & $0.219 * *$ & $0.349 * *$ & $0.271 * *$ & $0.357 * *$ & 0.731 & & & & & \\
\hline 7. Gident & $0.203 * *$ & -0.057 & -0.057 & $-0.083 *$ & 0.068 & -0.026 & & & & & \\
\hline 8. Male & $0.122 * *$ & -0.038 & 0.028 & $0.153 * *$ & $-0.181 * *$ & $-0.078 *$ & 0.070 & & & & \\
\hline 9. Experience & $0.092 *$ & 0.062 & $-0.087 *$ & -0.041 & -0.008 & 0.046 & $0.129 * *$ & $0.150 * *$ & & & \\
\hline 10. Position & $0.234 * *$ & -0.021 & $-0.084 *$ & -0.060 & $-0.085^{*}$ & -0.013 & $0.241 * *$ & $0.143 * *$ & $0.471 * *$ & & \\
\hline 11. Self.rated.perf & $0.367 * *$ & $0.146 * *$ & 0.052 & 0.042 & $-0.111 * *$ & $-0.079 *$ & $0.210 * *$ & 0.050 & $0.126 * *$ & $0.346 * *$ & 0.786 \\
\hline
\end{tabular}

Bold diagonals are the square root of the AVE

${ }^{*} p<0.05 ; * * p<0.01$

\section{Appendix 2: Construct Items/Survey Questions}

\section{Group Identification}

Please describe your relationship with the research group you belong to by using the following diagrams. With research group we mean the unit or group (research group, subject area, institute, department, etc.) that you are most committed to. Imagine that the circles at the left represent your own researcher identity, while the circles at the right represent the identity of your group. Which of the following options best describes the level of overlap between the two identities?
1.<smiles>C1CCCCCCC1</smiles><smiles>C1CCCCCCC1</smiles>

2.

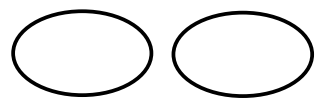

3.

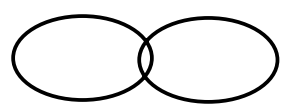

4.

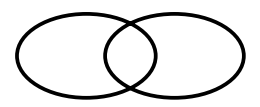

5.

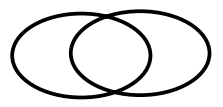

6.

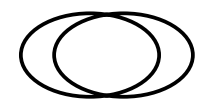

7.

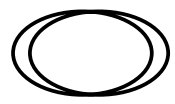

8.



far apart

close together, but separate

very small overlap

small overlap

Moderate overlap

large overlap

very large overlap

complete overlap 


\section{Performance Measure Emphasis}

How important are quantitative measures of research performance (e.g., the number of publications, citations, Web of Science impact factor, Norwegian list, etc.) for:

- Awarding promotion and tenure

- Appointing new faculty and staff members

- Allocating faculty funding and other internal resources for research

- Determine individual pay

Scale: 1 Not at all important- 5 very important (note: the Norwegian list is a science wide ranking list used by some universities in Sweden).

\section{Peer pressure}

How would you describe the collegial climate at your workplace?

- We openly express our dissatisfaction with colleagues who do not follow the group norm

- If a colleague underperforms in terms of research, we let her/him know

- Among colleagues, there is a large focus on research output in terms of journal publications

- If a colleague does not live up to the established research norm, it is not unusual that s/he quits or engages in administrative or teaching activities

Scale: 1 Strongly disagree; 5 Strongly agree.

\section{Competitiveness}

To what extent do you agree with the following statements:

- I enjoy the challenge of competing against others to succeed

- It is important to me to do better than others

\section{Rivalry}

To what extent do you agree with the following statements:

- Successful research builds on the fact that some are favored and others are disfavoured

- Competition for research grants leads to better research compared to a model where all permanent faculty is given equal opportunities to do research

Scale: 1 Not at all; 5 To a very high extent.

\section{Cynism}

To what extent do you agree with the following statements:

- When someone does me a favor at work, I know they expect one in return

- Universities are successful by taking advantage of hardworking lecturers and professors (excluded from measure)

- When you come right down to it, people within the university seldom do things if they do not profit from it

Scale: 1 Not at all; 5 To a very high extent.

\section{Corrupt}

To what extent do you agree with the following statements:

- I believe that some researchers stretch the truth to get their research published

- A great deal of research is either irrelevant or of low quality

Scale: 1 Not at all; 5 To a very high extent.

\section{Self-rated performance (control)}

How would you rate your own performance compared with peers on your academic level on the following dimensions?:

- Number of publications in scientific journals

- The quality of published journal articles

- External research grants won

Scale: 1 Much lower than my peer-2-3 At the same level as my peers; 4-5 Much higher than my peers.

\section{Marker variable (method/CMV-variable)}

To what extent do you use library databases in order to:

- Search for research in general

- Make literature reviews

- Follow the development in your research area

Scale: 1 Not at all; 5 To a very high extent.

\section{References}

Albu, C. N., \& Albu, N. (2015). Introduction to the special issue on accounting academia in Central and Eastern Europe. Accounting and Management Information Systems, 14(2), 247-274. 
Andersson, L. M. (1996). Employee cynicism: An examination using a contract violation framework. Human Relations, 49(11), $1395-1418$.

Andersson, L. M., \& Bateman, T. S. (1997). Cynicism in the workplace: Some causes and effects. Journal of Organizational Behavior, 18(5), 449-469.

Ashforth, B. E. (2016). Distinguished scholar invited essay: Exploring identity and identification in organizations: Time for some course corrections. Journal of Leadership \& Organizational Studies, 23(4), 361-373.

Ashforth, B. E., Mael, F. (1989) Social Identity Theory and the Organization. Academy of Management Review 14(1):20-39

Axelrod, R. (1984). The evolution of cooperation. New York: Basic Books.

Barker, J. (1993). Tightening the iron cage: Concertive control in self-managing teams. Administrative Science Quarterly, 38(3), 408-437.

Bartel, C. A. (2001). Social comparisons in boundary-spanning work: Effects of community outreach on members' organizational identity and identification. Administrative Science Quarterly, 46(3), 379-413.

Bergami, M., \& Bagozzi, R. P. (2000). Self-categorization, affective commitment and group self-esteem as distinct aspects of social identity in the organization. British Journal of Social Psychology, 39(4), 555-577.

Boulton, G., \& Lucas, C. (2011). What are universities for? Chinese Science Bulletin, 56(23), 2506-2517.

Bush, G. P., \& Hattery, L. H. (1956). Teamwork and creativity in research. Administrative Science Quarterly, 1, 361-372.

Chang, S. J., Van Witteloostuijn, A., \& Eden, L. (2010). From the editors: Common method variance in international business research. Journal of International Business Studies, 41(2), 178-184. https ://doi.org/10.1057/jibs.2009.88.

Chatelain-Ponroy, S., Mignot-Gérard, S., Musselin, C., \& Sponem, S. (2018). Is commitment to performance-based management compatible with commitment to university "publicness"? Academics' values in French universities. Organization Studies, 39(10), 1377-1401.

Cohen, T. R., Montoya, R. M., \& Insko, C. A. (2006). Group morality and intergroup relations: Cross-cultural and experimental evidence. Personality and Social Psychology Bulletin, 32(11), $1559-1572$.

Dean, J. W., Jr., Brandes, P., \& Dharwadkar, R. (1998). Organizational cynicism. Academy of Management Review, 23(2), 341-352.

DeChurch, L. A., \& Mesmer-Magnus, J. R. (2010). The cognitive underpinnings of effective teamwork: A meta-analysis. Journal of Applied Psychology, 95(1), 32.

De Jong, B. A., Bijlsma-Frankema, K. M., \& Cardinal, L. B. (2014). Stronger than the sum of its parts? The performance implications of peer control combinations in teams. Organization Science, 25(6), 1703-1721.

Deutsch, M. (1949). A theory of co-operation and competition. Human Relations, 2(2), 129-152.

Ellemers, N., Spears, R., \& Doosje, B. (2002). Self and social identity. Annual Review of Psychology, 53(1), 161-186.

Englund, H., \& Gerdin, J. (2020). Contesting conformity: How and why academics may oppose the conforming influences of intraorganizational performance evaluations. Accounting, Auditing \& Accountability Journal, 33(5), 913-938.

Falkenberg, L., \& Herremans, I. (1995). Ethical behaviours in organizations: Directed by the formal or informal systems? Journal of Business Ethics, 14(2), 133-143.

Fornell, C., \& Larcker, D. F. (1981). Evaluating structural equation models with unobservable variables and measurement error. Journal of Marketing Research, 18(1), 39-50.
Franco-Santos, M., \& Doherty, N. (2017). Performance management and well-being: A close look at the changing nature of the UK higher education workplace. The International Journal of Human Resource Management, 28(16), 2319-2350.

Frey, B. S., Homberg, F., \& Osterloh, M. (2013). Organizational control systems and pay-for-performance in the public service. Organization Studies, 34(7), 949-972.

Gendron, Y. (2008). Constituting the academic performer: The spectre of superficiality and stagnation in academia. European Accounting Review, 17(1), 97-127.

Gendron, Y. (2015). Accounting academia and the threat of the payingoff mentality. Critical Perspectives on Accounting, 26, 168-176.

Goebel, S., \& Weißenberger, B. E. (2017). The relationship between informal controls, ethical work climates, and organizational performance. Journal of Business Ethics, 141(3), 505-528.

Guastello, S. J., Rieke, M. L., Guastello, D. D., \& Billings, S. W. (1992). A study of cynicism, personality, and work values. The Journal of Psychology, 126(1), 37-48.

Hair, J., Anderson, R., Tatham, R., \& Black, W. (2010). Multivariate data analysis. A global perspective (7th ed.). Upper Saddle, NJ: Prentice sHall.

Henseler, J., Ringle, C. M., \& Sarstedt, M. (2015). A new criterion for assessing discriminant validity in variance-based structural equation modeling. Journal of the Academy of Marketing Science, 43(1), 115-135.

Hiebl, M. R., \& Richter, J. F. (2018). Response rates in management accounting survey research. Journal of Management Accounting Research, 30(2), 59-79.

Jackson, J. W. (1993). Realistic group conflict theory: A review and evaluation of the theoretical and empirical literature. Psychological Record, 43(3), 395-415.

Jacobsen, C. B., \& Andersen, L. B. (2014). Performance management for academic researchers: How publication command systems affect individual behavior. Review of public personnel administration, 34(2), 84-107.

Jöreskog, K. G., \& Yang, F. (1996). Nonlinear structural equation models: The Kenny-Judd model withinteraction effects. In G. A. Marcoulides \& R. E. Schumacker (Eds.), Advanced structural equation modeling: Issues and techniques (pp. 57-88). Mahwah, NJ: Lawrence Erlbaum Associates Inc.

Kallio, K. M., Kallio, T. J., Tienari, J., \& Hyvönen, T. (2016). Ethos at stake: Performance management and academic work in universities. Human Relations, 69(3), 685-709.

Kish-Gephart, J. J., Harrison, D. A., \& Treviño, L. K. (2010). Bad apples, bad cases, and bad barrels: meta-analytic evidence about sources of unethical decisions at work. Journal of Applied Psychology, 95(1), 1.

Kish-Gephart, J., Detert, J., Treviño, L. K., Baker, V., \& Martin, S. (2014). Situational moral disengagement: Can the effects of self-interest be mitigated? Journal of Business Ethics, 125(2), 267-285.

Kline, R. B. (2011). Principles and practice of structural equation modeling. New York, NY: Guilford Press.

Knights, D., \& Clarke, C. A. (2014). It's a bittersweet symphony, this life: Fragile academic selves and insecure identities at work. Organization Studies, 35(3), 335-357.

Komorita, S. S., \& Parks, C. D. (1995). INTERPERSONAL relations: Mixed-motive interaction. Annual Review of Psychology, 46(1), 183-207.

Leung, K., Li, F., \& Zhou, F. (2012). Sex differences in social cynicism across societies: The role of men's higher competitiveness and male dominance. Journal of Cross-Cultural Psychology, 43(7), $1152-1166$.

Lindell, M. K., \& Whitney, D. J. (2001). Accounting for common method variance in cross-sectional research designs. Journal of Applied Psychology, 86(1), 114. 
Loughry, M. (2010). Peer control in organizations. In S. B. Sitkin, L. B. Cardinal, \& K. M. Bijlsma-Frankema (Eds.), Organizational control (pp. 324-361). Cambridge: Cambridge University Press.

Luft, J., \& Shields, M. D. (2003). Mapping management accounting: Graphics and guidelines for theory-consistent empirical research. Accounting, Organizations and Society, 28(2-3), 169-249.

Maitland, I. (2002). The human face of self-interest. Journal of Business Ethics, 38(1-2), 3-17.

Malsch, B., \& Tessier, S. (2015). Journal ranking effects on junior academics: Identity fragmentation and politicization. Critical Perspectives on Accounting, 26, 84-98.

Miller, P., \& Power, M. (2013). Accounting, organizing, and economizing: Connecting accounting research and organization theory. Academy of Management Annals, 7(1), 557-605.

Mirvis, P., \& Kanter, D. (1989). Combating cynicism in the workplace. National Productivity Review, 8(4), 377-394.

Mirvis, P., \& Kanter, D. (1991). Beyond demography: A psychographic profile of the workforce. Human Resource Management, 30(1), $45-68$.

Northcott, D., \& Llewellyn, S. (2003). The 'ladder of success' in healthcare: The UK national reference costing index. Management Accounting Research, 14(1), 51-66.

Ouchi, W. G. (1980). Markets, bureaucracies, and clans. Administrative science quarterly, 129-141.

Parker, L. D. (2011). University corporatisation: Driving redefinition. Critical Perspectives on Accounting, 22(4), 434-450.

Parker, L. D. (2013). Contemporary university strategising: The financial imperative. Financial Accountability \& Management, 29(1), $1-25$.

Pinter, B., Insko, C. A., Wildschut, T., Kirchner, J. L., Montoya, R. M., \& Wolf, S. T. (2007). Reduction of interindividual-intergroup discontinuity: The role of leader accountability and proneness to guilt. Journal of Personality and Social Psychology, 93(2), 250.

Podsakoff, P. M., MacKenzie, S. B., Lee, J.-Y., \& Podsakoff, N. P. (2003). Common method biases in behavioral research: A critical review of the literature and recommended remedies. Journal of Applied Psychology, 88(5), 879-890.

Sarstedt, M., Hair, J. F., Ringle, C. M., Thiele, K. O., \& Gudergan, S. P. (2016). Estimation issues with PLS and CBSEM: Where the bias lies! Journal of Business Research, 69(10), 3998-4010.

Schopler, J., \& Insko, C. A. (1992). The discontinuity effect in interpersonal and intergroup relations: Generality and mediation. European Review of Social Psychology, 3(1), 121-151.

Schopler, J., Insko, C. A., Drigotas, S. M., Wieselquist, J., Pemberton, M. B., \& Cox, C. (1995). The role of identifiability in the reduction of interindividual-intergroup discontinuity. Journal of Experimental Social Psychology, 31(6), 553-574.

Schumpeter, J. A. (1942). Capitalism, socialism and democracy. New York: Harper and Brothers.

Sharma, S., Durand, R. M., \& Gur-Arie, O. (1981). Identification and analysis of moderator variables. Journal of Marketing Research, $18(3), 291-300$

Shleifer, A. (2004). Does competition destroy ethical behavior? American Economic Review, 94(2), 414-418.
Simmons, C. H., Wehner, E. A., Tucker, S. S., \& King, C. S. (1988). The cooperative/competitive strategy scale: A measure of motivation to use cooperative or competitive strategies for success. The Journal of Social Psychology, 128(2), 199-205.

Speklé, R. F., \& Widener, S. K. (2018). Challenging issues in survey research: Discussion and suggestions. Journal of Management Accounting Research, 30(2), 3-21.

Stoelhorst, J. W., \& Richerson, P. J. (2013). A naturalistic theory of economic organization. Journal of Economic Behavior \& Organization, 90, 45-56.

Su, S., \& Baird, K. (2017). The association between performance appraisal systems, work-related attitudes and academic performance. Financial Accountability \& Management, 33(4), 356-372.

Tenbrunsel, A. E., \& Messick, D. M. (1999). Sanctioning systems, decision frames, and cooperation. Administrative Science Quarterly, 44(4), 684-707.

Ter Bogt, H. J., \& Scapens, R. W. (2012). Performance management in universities: Effects of the transition to more quantitative measurement systems. European Accounting Review, 21(3), 451-497.

Treviño, L. K., Den Nieuwenboer, N. A., \& Kish-Gephart, J. J. (2014). (Un)ethical behavior in organizations. Annual Review of Psychology, 65, 635-660.

Turner, J. C., \& Tajfel, H. (1986). The social identity theory of intergroup behavior. Psychology of Intergroup Relations, 5, 7-24.

Turner, J. H., \& Valentine, S. R. (2001). Cynicism as a fundamental dimension of moral decision-making: A scale development. Journal of Business Ethics, 34(2), 123-136.

Vesty, G., Sridharan, V. G., Northcott, D., \& Dellaportas, S. (2018). Burnout among university accounting educators in Australia and New Zealand: Determinants and implications. Accounting \& Finance, 58(1), 255-277.

Vice, S. (2011). Cynicism and morality. Ethical Theory and Moral Practice, 14(2), 169-184.

Victor, B., \& Cullen, J. B. (1988). The organizational bases of ethical work climates. Administrative Science Quarterly, 33, 101-125.

Vogel, R., \& Hattke, F. (2018). How is the use of performance information related to performance of public sector professionals? Evidence from the field of academic research. Public Performance \& Management Review, 41(2), 390-414.

Wade, M. J. (1977). An experimental study of group selection. Evolution, 31(1), 134-153.

Wanous, J. P., Reichers, A. E., \& Austin, J. T. (2000). Cynicism about organizational change: Measurement, antecedents, and correlates. Group and Organization Management, 25, 132-153.

Wildschut, T., Pinter, B., Vevea, J. L., Insko, C. A., \& Schopler, J. (2003). Beyond the group mind: A quantitative review of the interindividual-intergroup discontinuity effect. Psychological Bulletin, 129(5), 698.

Wilson, D. S., \& Sober, E. (1994). Reintroducing group selection to the human behavioral sciences. Behavioral and brain sciences, 17(4), 585-608.

Publisher's Note Springer Nature remains neutral with regard to jurisdictional claims in published maps and institutional affiliations. 